\title{
An Empirical Study on the Relationship between Fiscal Expenditure on Science and Technology and Technology Innovation in China
}

\author{
Shengqiang LIU \\ Xiamen University, Xiamen, China 361005 \\ Chongqing Technology and Business University, Chongqing, China 400067
}

\begin{abstract}
Base on the data in China from 1985 to 2012, this paper studies the relationship between fiscal expenditure on science and technology and technology innovation (patent applications) by using cointegration analysis and Granger cause test. The results show that: Although the fiscal expenditure on science and technology and technology innovation (patent applications) are fluctuant respectively, the long term relationship between them is stable and co-integrative. China's fiscal expenditure on science and technology has a great role in promoting technological innovation and they are Granger cause of each other.
\end{abstract}

KEYWORD: Fiscal Expenditure on Science and Technology; Technology Innovation.

\section{INTRODUCTION}

With the continuous rise of the knowledge economy and the acceleration of global economic integration process, the importance of technological innovation for a country or business has been widely recognized and accepted. Due to technological innovation is a quasi- public goods and it has the characteristics of high investment risk, long cycle, earnings uncertainty etc, the enthusiasm of enterprises for independent innovation is generally is not high. So it is objective demand governments at all level to come up with some fiscal resources to support and encourage enterprise to innovate. Base on the data of china from 1985 to 2012, this paper studies the relationship between fiscal expenditure on science and technology and technological innovation by using co-integration analysis and Granger cause test hoping to provide some empirical evidence for evaluation of fiscal investment in science and technology and innovation policy effect.

\section{DATA SOURCE AND DESCRIPTION}

Because domestic patent applications in China began in 1985 and the Statistical Yearbook data disclosed only to 2012, the paper selects the number of patent applications ( $\mathrm{Pa}$, unit: piece) as a measure of technological innovation and selects fiscal expenditure science (Fexp, unit: million) as a measure of fiscal expenditure on science and technology indicators in china from 1985 to 2012.
The data of patent applications is from the State Intellectual Property Office website People's Republic of China (http://www.sipo.gov.cn/tjxx/) and the data of fiscal expenditure is from Chinese Statistical Yearbook. In order to eliminate the effects of inflation on actual value, this paper, firstly adjust the book value of fiscal expenditure (Fexp) to the actual value (PFexp) on the base of constant prices in 1978, and then calculate the natural logarithm of the actual fiscal expenditure (PFexp) and the natural logarithm of patent $(\mathrm{LnPa})$. This treatment can not only avoid the volatility in the data, but also can eliminate the influence of heteroscedasticity. This change does not affect the long-term and stable relations between variables.

There are many reasons for choosing the data of patent application rather than patent license as the measure tool of technological innovation but the main three are as follows: (1)There is a strong positive relationship between patent application and patent license and the data of patent application contains a large mount of the information of patent license; (2) The information lag of the patent license is larger then the patent application and there are more information distortion in the data of the patent license then the patent application; (3)the gap between them is due to the more the for license, the imperfect intermediary organizations and the inefficiently of the licensing authority. 
Table 1: Fiscal expenditure on science and technology and patent application in china from 1985 to 2012

\begin{tabular}{|c|c|c|l|l|l|}
\hline Year & $\begin{array}{l}\text { Book value } \\
\text { of fiscal } \\
\text { expenditure } \\
\text { (Fexp,100 } \\
\text { million) }\end{array}$ & $\begin{array}{l}\text { Price } \\
\text { index } \\
\text { (P) }\end{array}$ & $\begin{array}{l}\text { The } \\
\text { natural } \\
\text { logarithm } \\
\text { of PFexp } \\
\text { (LnPFexp) }\end{array}$ & $\begin{array}{l}\text { The data of } \\
\text { patent } \\
\text { application } \\
\text { Pa) }\end{array}$ & $\begin{array}{l}\text { The natural } \\
\text { logarithm } \\
\text { of } \\
\text { Pa(LnPa) }\end{array}$ \\
\hline 1985 & 102.59 & 1.311 & 4.35995 & 14372 & 9.57304 \\
\hline 1986 & 112.57 & 1.396 & 4.38996 & 18509 & 9.82601 \\
\hline 1987 & 113.79 & 1.498 & 4.33022 & 26077 & 10.16881 \\
\hline 1988 & 121.12 & 1.779 & 4.22073 & 34011 & 10.43444 \\
\hline 1989 & 127.87 & 2.099 & 4.10955 & 32905 & 10.40138 \\
\hline 1990 & 139.12 & 2.164 & 4.16338 & 41469 & 10.63270 \\
\hline 1991 & 160.69 & 2.238 & 4.27389 & 50040 & 10.82058 \\
\hline 1992 & 189.26 & 2.381 & 4.37560 & 67135 & 11.11446 \\
\hline 1993 & 225.61 & 2.731 & 4.41414 & 77276 & 11.25514 \\
\hline 1994 & 268.25 & 3.390 & 4.37109 & 77735 & 11.26106 \\
\hline 1995 & 302.36 & 3.969 & 4.33310 & 83045 & 11.32714 \\
\hline 1996 & 348.63 & 4.299 & 4.39563 & 102735 & 11.53991 \\
\hline 1997 & 408.86 & 4.419 & 4.52746 & 114208 & 11.64578 \\
\hline 1998 & 438.6 & 4.384 & 4.60563 & 121989 & 11.71169 \\
\hline 1999 & 543.85 & 4.322 & 4.83496 & 134239 & 11.80738 \\
\hline 2000 & 575.62 & 4.340 & 4.88757 & 170682 & 12.04756 \\
\hline 2001 & 703.26 & 4.370 & 5.08096 & 203573 & 12.22378 \\
\hline 2002 & 816.22 & 4.335 & 5.23796 & 252631 & 12.43969 \\
\hline 2003 & 975.54 & 4.387 & 5.40435 & 308487 & 12.63943 \\
\hline 2004 & 1095.34 & 4.558 & 5.48194 & 353807 & 12.77651 \\
\hline 2005 & 1334.91 & 4.640 & 5.66190 & 476264 & 13.07373 \\
\hline 2006 & 1688.5 & 4.710 & 5.88191 & 573178 & 13.25895 \\
\hline 2007 & 1783.04 & 4.936 & 5.88952 & 693917 & 13.45011 \\
\hline 2008 & 2129.21 & 5.227 & 6.00967 & 828328 & 13.62716 \\
\hline 2009 & 2744.52 & 5.190 & 6.27063 & 976686 & 13.79192 \\
\hline 2010 & 3250.18 & 5.361 & 6.40732 & 1222286 & 14.01623 \\
\hline 2011 & 3828.02 & 5.650 & 6.51845 & 1633347 & 14.30614 \\
\hline 2012 & 4452.63 & 5.797 & 6.64391 & 2050649 & 14.53367 \\
\hline
\end{tabular}

Figures 1 is the time sequence graph of the natural logarithm of actual fiscal expenditure on science and technology (LnPFexp) and figure 2 is the time sequence graph of the natural logarithm of patent application ( $\mathrm{LnPa})$. It can be seen from the figure 1 and figure 2 that LnPFexp and $\mathrm{LnPa}$ change in the same direction and almost appear the same pace which indicates that there is a Long-run equilibrium relationship between them.

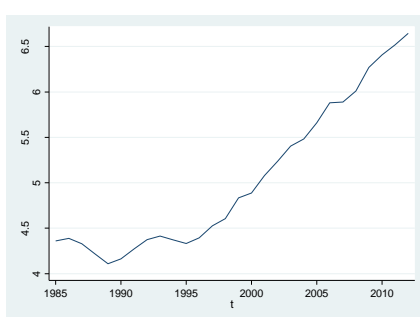

Figure 1: Time sequence graph of LnPFexp

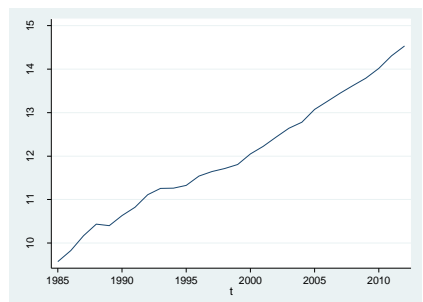

Figure 2: Time sequence graph of $\mathrm{LnPa}$

\section{MODEL AND THE RESULT ANALYSIS}

Co-integration relationship reflects the existence of a long-run equilibrium relationship between the variables. In some economic sense, the cointegration relationship reveal it can be affected the change of one variable by changes in another variable. The two economic variables cannot be too far from each other. A shock can make them deviate from each other only in the short term and will automatically return to equilibrium position in the long term. Before using the co-integration test, you must first check whether the variables are stable, if the variables are not stable, it may be spurious regression. Due to the more commonly-used test method of DF test does not guarantee equation residuals are white noise, so Dickey and Fuller develop the DF test method to form the ADF test method which is currently application of common.

\subsection{The stability test}

In order to determine the integration ranks, this paper do the ADF test. Table 2 show that the ADF value of LnPFexp's original sequence, the first-order difference and LnPa's original sequence are greater than the critical value of $1 \%$ significance level, but the ADF value of LnPFexp's second-order difference, LnPa's first-order and second-order difference are less than the critical value of the $5 \%$ significance level. Therefore is LnPFexp the original sequence, the first-order difference and $\mathrm{LnPa}$ LnPFexp original sequence is not stable, but LnPFexp second-order difference, $\mathrm{LnPa}$ first difference and second order difference is stable, there will be a co-integration relationship between them. According to the co-integration theory, if the variables are not stable while its difference are stable and the linear combination of them is stable, so can preliminary determination that LnPFexp and $\mathrm{LnPa}$ reached a stable, namely $\mathrm{LnPFexp}$ and $\mathrm{LnPa}$ are the second order single whole sequence and it can further test the co-integration relationship between the two variables.

Table 2: Augmented Dickey-Fuller test results for unit root

\begin{tabular}{|c|c|c|c|c|}
\hline \multirow{2}{*}{$Z(t)$} & \multirow{2}{*}{$\begin{array}{c}\text { ADF est } \\
\text { statistic }\end{array}$} & \multicolumn{2}{|c|}{$\begin{array}{c}\text { Interpolated } \\
\text { Dickey-Fuller }\end{array}$} & \multirow{2}{*}{ Conclusion } \\
\cline { 3 - 4 } & & $1 \%$ & $5 \%$ & \\
\hline LnPFexp & 1.346 & -3.743 & -2.997 & No \\
\hline LnPa & 0.586 & -3.743 & -2.997 & No \\
\hline D.LnPFexp & -2.463 & -3.750 & -3.000 & No \\
\hline D.LnPa & -4.080 & -3.750 & -3.000 & Yes \\
\hline D2.LnPFexp & -5.374 & -3.750 & -3.000 & Yes \\
\hline D2.LnPa & -5.380 & -3.750 & -3.000 & Yes \\
\hline
\end{tabular}




\subsection{The optimal lag order}

In general, before doing the co-integration analysis, we should determine the optimal lag order of VAR model. This paper will be based on the unconstrained (Unrestricted) VAR model level to determine the co-integration order. The method of determining the optimal lag order is from large lag order to small according to the corresponding the value of LR, FPE, AIC HQIC and SBIC. As shown in table 3 , all the above five critical value indicate the optimal lag order is one, so the study will develop on the base of the VAR (1) model.

Table 3: The optimal lag order of VAR model

\begin{tabular}{|c|c|c|c|c|c|c|c|}
\hline & LL & LR & P & FPE & AIC & HQIC & SBIC \\
\hline 0 & -18.834 & & & 0.01946 & 1.7362 & 1.7622 & 1.8344 \\
\hline 1 & 60.609 & $158.89^{*}$ & 0.000 & $0.00004^{*}$ & $-4.5507^{*}$ & $-4.4726^{*}$ & $-4.2562^{*}$ \\
\hline 2 & 62.599 & 3.981 & 0.409 & 0.00004 & -4.3832 & -4.2530 & -3.8924 \\
\hline
\end{tabular}

Note: * indicates the optimal lag order decided by the judgment rule

\subsection{The number of co-integration equation}

Before co-integration analysis, we must not only determine the optimal lag order, but also determine the existence and number of co-integration. The test results of the rail statistics in table 4 are significant under 5\% level, which indicate that there is at least one co-integration vector between the LnPFexp and the $\mathrm{LnPa}$. That is to say, there is a long-term equilibrium relationship between LnPFexp and $\mathrm{LnPa}$ during 1985-2012.

Table 4: The test results to determine the number of Cointegration equation

\begin{tabular}{|c|c|c|c|c|}
\hline $\begin{array}{c}\text { The number of } \\
\text { co-integration }\end{array}$ & LL & Eigenvalue & Trace statistic & $5 \%$ \\
\hline 0 & 54.492004 & & 27.5763 & 15.41 \\
\hline 1 & 66.857748 & 0.61373 & $2.8448^{*}$ & 3.76 \\
\hline 2 & 68.28016 & 0.10364 & & \\
\hline
\end{tabular}

\subsection{Co-integration test}

This paper is planed to test the co-integration relationship between LnPFexp and $\mathrm{LnPa}$ by using Engle-Granger' method. The result revealing the long-term equilibrium relationship and short-term dynamic relationship equations of them are as follows:

$$
\begin{aligned}
& \text { D.LnPFexp }=0.1436689^{* *} \times\left(\mathrm{D} . \mathrm{LnPa}-1.46973^{* *} \times \mathrm{LnPFexp}+0.109077\right. \\
& \text { (2.85) } \quad(-17.20) \\
& +\left[0.0821533 \times \mathrm{D} \_l n z l-0.3179513 \times \mathrm{LnPFexp}+0.52522^{* *}\right] \\
& \text { (0.42) (1.85) (2.86) } \\
& \text { D.LnPa }=-0.1475394 * * \times(\text { D.LnPa-1.46973**×LnPFexp }-5.075141) \\
& (-2.93) \quad(-17.20) \\
& +\left[-0.127117 \times \mathrm{D} \_l n z l+0.391878 * \times \mathrm{D} . \mathrm{LnPFexp}+0.1062155^{* *}\right] \\
& (-0.65) \\
& \text { (2.27) } \\
& \text { (2.78) }
\end{aligned}
$$

The data in brackets under co-integration equation is $t$ test value of the parameter, $* *$ indicates $1 \%$ significance level and * indicates $5 \%$ significance level. The estimated result shoe that, R2 is equal to 0.981262 and the value of the AIC and SC are relatively small which show that the degree of reliability estimation equation and fitting are good in a whole. The equation coefficient estimation has a high degree of reliability. At the same time, residual test results show that ADF test value is 4.54672 which corresponding the critical values is -4.183 under the 5\% significant level, The null hypothesis should be rejected, so the residual is stable. There is long-term stabile co-integration relationship between fiscal expenditure on science and technology and technological innovation. The ratio between them is 1:1.46973 to changes.

In $\mathrm{LnPa}$ equation, $\mathrm{LnPa}$ adjust speed is negative 0.1475394 and significant at the $1 \%$ level which indicate that LnPFexp is dominant on the cointegration. When the number of $\mathrm{LnPa}$ is relatively low or deviate from the long-run equilibrium state, it will quickly adjust toward LnPFexp. In LnPFexp equation, LnPFexp adjust speed is positive 0.1436689 and also significant at the $1 \%$ level which indicate that LnPFexp is dominant on the cointegration. LnPFexp is not affected by $\mathrm{LnPa}$.

\subsection{The graph of pulse reflected}

LnPFexp dominates on the co-integration relationship which is clearly described in the graph of pulse reflected. Figure 3 is the pulse reflected graph of LnPFexp to LnPa. Figure 3 shows that the impact pulse begins to rise, and then gradually is stable at 0.55 in the third period which indicate LnPFexp growth will cause $\mathrm{LnPa}$ growth in the behind growth period, and the elasticity coefficients is stable. Figure 4 is the pulse reflected graph of $\mathrm{LnPa}$ to LnPFexp. Figure 4 shows that the impact pulse begins to rise, and then decline from the peak of 0.71 in the third period and financially is stable at 0.66 in the ninth period which indicate LnPFexp growth will cause $\mathrm{LnPa}$ in the behind growth period and the elasticity coefficients is stable. The increase of $\mathrm{LnPa}$ can also cause the increase of LnPFexp. The slightly fluctuations in figure 4 may be due to the degree of industrialization is not high. 


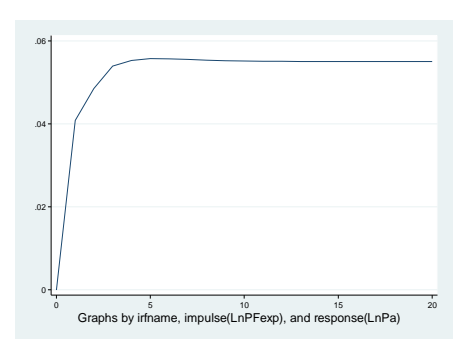

Figure 3: The pulse reflected graph of LnPFexp to $\mathrm{LnPa}$

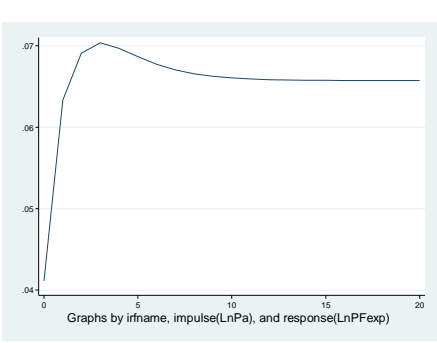

Figure 4: The pulse reflected graph of LnPa to LnPFexp

\subsection{Granger-cause test}

The co-integration test results show that there exists a long-term co-integration relationship between fiscal expenditure on science and technology and patent, while the co-integration relationship can not determine whether there is statistically a causal relationship between them but it can reveal it is possible to have Granger cause. Whether this equilibrium relationship form the increase of Granger cause is from fiscal expenditure on science and technology and patent need to further verify. Base on VAR model, this paper uses granger cause test to verify the causal relationship between them. It is showed that fiscal expenditure on science and technology and patent are granger cause each other at the $95 \%$ critical level in the lag period of 1 year, 2 year and 3 year.

Table 5: Granger-cause test result between variables

\begin{tabular}{|c|c|c|c|c|}
\hline H0 & Lag & $\mathrm{F}(1,24)$ & Prob> F & Conclusion \\
\hline $\begin{array}{c}\text { LnPFexp does not } \\
\text { Granger-cause LnPa }\end{array}$ & & 10.81 & 0.0031 & No \\
\cline { 1 - 3 } $\begin{array}{c}\text { LnPa does not } \\
\text { Granger-cause LnPFexp }\end{array}$ & & 7.00 & 0.0141 & No \\
\hline $\begin{array}{c}\text { LnPFexp does not } \\
\text { Granger-cause LnPa }\end{array}$ & \multirow{2}{*}{2} & 5.87 & 0.0095 & No \\
\hline $\begin{array}{c}\text { LnPa does not } \\
\text { Granger-cause LnPFexp }\end{array}$ & & 4.37 & 0.0260 & No \\
\hline $\begin{array}{c}\text { LnPFexp does not } \\
\text { Granger-cause LnPa }\end{array}$ & \multirow{2}{*}{3} & 4.21 & 0.0202 & No \\
\cline { 1 - 2 } $\begin{array}{c}\text { LnPa does not } \\
\text { Granger-cause LnPFexp }\end{array}$ & & 3.62 & 0.0334 & No \\
\hline
\end{tabular}

\section{CONCLUSION AND SUGGESTION}

By using co-integration analysis and granger cause test, this paper empirically investigate the relationship between fiscal expenditure on science and technology and technological innovation in China from 1985 to 2012. The results show that: (1) According to the co-integration test, there is a strong relationship between fiscal expenditure on science and technology and technological innovation. Although their growth is not stable, but the second order difference is stable. There is a long-term stable equilibrium relationship between them. The elasticity coefficient is 1.46973 and the corresponding adjustment speed is 0.1475394 which show that China's fiscal expenditure on science and technology has a great role in promoting technological innovation; (2) According to the Granger cause test, fiscal expenditure on science and technology and patent are granger cause each other at the $95 \%$ critical level in the lag period of 1 year, 2 year and 3 year. The increase of fiscal expenditure on science and technology will promote the increase of technical innovation, in turn, the increase of technical innovation also has an obvious effect on the increase of fiscal expenditure on science and technology. It can be form a virtuous mutual promoted mechanism.

Based on the above analysis, the writer proposes that, it should be further strengthen fiscal expenditure on science and technology. LnPFexp is not only to increase the total amount, but also optimize the structure, and should be institutionalized to ensure the sustainability of LnPFexp. at the same time, the writer suggests to strengthen the protection of intellectual property rights and to follow the principle of "who invests, who benefits" and to establish a diversified investment organization such as government, enterprises and civil institutions, so that the virtuous mutual promoted mechanism can play its due role.

\section{ACKNOWLEDGEMENT}

This paper is sponsored by the national social science funds (Grant NO: 14BJY083), the Humanities and Social Sciences Research Project from the Ministry of Education (Grant NO: 11YJC630139) and Postdoctoral Funds of China (Grant NO: 2013M530305).

\section{REFERENCES}

[1] Arrow, K.. Economic welfare and the Allocation of Resources for Invention. Princeton University Press, 1962.

[2] Barro,R.. Government Spending in a Simple Model of Economic Growth. Journal of Political Economy, 1990, 98:103-125.

[3] Dominique, G., Bruno, V., and Pottelsberghe, D.. The Impact of Public R\&D Expenditure on Business R\&D. Economics of Innovation and New Technology, 2003, 12(3): 225-243.

[4] Holemans, B., and Sleuwaegen, L.. Innovation Expenditures and the Role of Government in Belgium. Research Policy, 1988, 17(6):375-379.

[5] Levin, R. C., and Reiss, P. C,. "Tests of a Schumpeterian Model of R\&D and Market Structure", in Griliches,Z.(ed.), R\&D,Patents and Productivity, Chicago: University of Chicago Press.1984.

[6] Wallste, S. J.. The Effects of Government-industry R\&D Programs on Private R\&D: The Case of the Small Business Innovation Research Program. The Rand journal of economics, 2000, 31(1): 82-100. 